\title{
O UNIVERSO DA LEITURA INSERIDO NO CONTEXTO DA SAÚDE MENTAL: UMA INVESTIGAÇÃO INSTITUCIONAL SOBRE AS LEITURAS EM MEIO AO EMOCIONAL E MOTIVACIONAL E SUAS INFLUÊNCIAS PSICOLÓGICAS NO CORPO DISCENTE DA UNIVERSIDADE FEDERAL DO PAMPA, CAMPUS SÃO GABRIEL
}

\author{
Luciano Samaniego Arrussul', Vera Lúcia Cardoso Medeiros² \\ 'Enfermeiro e Especialista em Educação: Interdisciplinaridade e Transversalidade, \\ Universidade Federal do Pampa, Campus São Gabriel. \\ oceanossul@bol.com.br \\ 2 Professora Adjunta da Unipampa - Campus Bagé. \\ vera.medeiros@unipampa.edu.br
}

\begin{abstract}
RESUMO
O presente artigo tem como finalidade apresentar os resultados de um questionário aplicado nos cursos de graduação da Universidade Federal do Pampa - Unipampa, campus São Gabriel, que teve como ênfase a leitura. O objetivo do referido questionário foi a verificação de quais os tipos de leitura e a frequência da mesma na vida desses acadêmicos. Os resultados nos mostram quais os tipos de leituras são feita e a frequência com que são realizadas pelos acadêmicos. Dessa forma, servindo como um instrumento demográfico dos leitores da universidade, além de abrir a possibilidade de identificar as potencialidades dos alunos e intervir nos possíveis problemas enfrentados na aquisição de conhecimento através de leitura.
\end{abstract}

Palavras Chaves: Leitura; Prazer; Conhecimento; Universidade.

\section{ABSTRACT}

This article aims to present the results of a questionnaire applied in undergraduate courses at the Federal University of Pampa - Unipampa, campus São Gabriel - Brazil, which had an emphasis on reading. The aim of the questionnaire was checking the types and frequency of reading the same in the lives of academics. The results show us what types of readings are made and the frequency with which they are carried out by academics. Thus, serving as an instrument of the university population of readers, and open the possibility of identifying the potential of students and intervene in potential problems faced in acquiring knowledge through reading.

Keywords: Reading; Pleasure; Knowledge; University.

\section{INTRODUÇÃO}

A leitura é um processo de compreensão de algum tipo de informação armazenada, podendo-se utilizar de código, como a linguagem. O código pode ser visual, auditivo e inclusive táctil, como o sistema Braille. Destacamos que nem todos os tipos de leitura se apoiam na linguagem é o caso, por exemplo, dos pictogramas ou ainda das partituras de música. 
O ato da leitura pode trazer muitos benefícios a quem a prática, os nossos antepassados já sabiam que através desse ato simples o homem pode tentar compreender seus problemas. Buscamos entender a nossa existência, as nossas angústias, nossos medos e incertezas. Assim, ao folhar um livro, ao ler matérias em meios virtuais ou impressos, procuramos conhecimentos, respostas para nossas dúvidas diárias, alento, conforto, paz e bem estar. A partir da leitura elaboramos ideias, construímos o conhecimento, nos aproximamos do mundo e das pessoas, elevamos nossa alma.

Este artigo tem a finalidade de apresentar os resultados da pesquisa realizada com os acadêmicos dos cursos de graduação da Universidade Federal do Pampa - UNIPAMPA, campus São Gabriel - RS.

A pesquisa teve o objetivo de realizar um levantamento demográfico dos leitores da universidade, através da aplicação de um questionário aos acadêmicos dos cursos de graduação da Universidade Federal do Pampa, Campus São Gabriel, no ano de 2011, caracterizando os hábitos de leitura dos alunos. Além disso esse estudo poderá servir como instrumento para intervenções nos possíveis problemas enfrentados na aquisição de conhecimento através de leitura.

\section{OS BENEFÍCIOS DA LEITURA}

Realizando um resgate na história da leitura, verificamos que a mesma era já utilizada no cuidado em saúde há alguns séculos antes da era cristã. Os antigos Hindus mantinham em seus hospitais, músicos, narradores de histórias e poetas para distrair os doentes. A leitura era um dos componentes da fórmula para a cura, assim como os seus remédios e procedimentos. Os benefícios da leitura eram extraídos para os doentes na sua recuperação.

Paixão (1979, p.22) diz que "os hospitais mais notáveis foram construídos por ordem do rei Asoka, cerca de 225 a.C. Nos hospitais da Índia havia músicos, narradores de histórias e poetas para distrair os doentes. Funcionavam também escolas de medicina".

Os Hindus, povos interessados pela cura, exigiam que seus enfermeiros tivessem asseio, habilidades, inteligência, conhecimento da arte culinária e de preparo dos remédios, deviam ser dedicados e cooperadores, o que nos faz crer que eles precisavam da leitura para alcançar as qualidades necessárias da profissão.

Os benefícios da leitura podem ser identificados desde as épocas em que a medicina era primitiva. Hoje, mesmo com o avanço da ciência e suas tecnologias, os benefícios continuam, e os cientistas podem identificar e comprovar os bons frutos da leitura.

A professora Doutora Nilma Gonçalves Lacerda, integrante do Núcleo de Tecnologia Educacional para a Saúde (NUTES), da Universidade Federal do Rio de Janeiro, docente em literatura, pesquisadora na arte da leitura e da escrita, realizou um estudo de caso no qual relata as experiências que teve quando era professora visitante no Laboratório de Linguagens e Mediações, no ano de 2004. O objetivo do seu trabalho foi acompanhar as relações entre leitura e saúde, visando à construção do corpo teórico capaz de fundamentar as diversas ações de leitura realizadas em espaços de cuidado em saúde, na compreensão de saúde como construção pessoal e social. A pesquisa propiciou à formação dos futuros pedagogos elementos conceituais para que a leitura contribua na educação integral do indivíduo, a saúde seja tratada como construção consciente, em que ganhe relevo o valor da leitura literária como experiência de enfrentamento do enigma da existência e dos rumos de escritas pessoais. A leitura não deve ser apenas vista com um olhar literário, mas também um instrumento capaz de transformação de atitude frente à vida, 
a partir da experiência da leitura. As palavras proporcionam ao leitor a perspectiva de realizar as escolhas internas que vão orientar a convivência com o enigma da existência.

No livro "Infância" de Graciliano Ramos é citada a experiência positiva que a leitura teve na auto-estima de um menino. $O$ ato de ler desvenda para o menino a saúde nas palavras, leva-o a interessar-se pelo mundo.

$\mathrm{Na}$ ficção apresentada por um pai injusto, que o menino Graciliano vai trocar a autoimagem depreciada, por uma atitude afirmativa. Ao ver espelhado os seres de palavras sobre papel, um abandono semelhante ao seu, o menino empreende a aventura da alfabetização, norteando de outra forma sua identificação, sua existência.

Aos nove anos, eu era quase analfabeto. E achava-me inferior aos Mota Lima, nossos vizinhos, muito inferior, construído de maneira diversa.

(....)

Ora, uma noite, depois do café, meu pai me mandou buscar um livro na cabeceira da cama. (....) Explicou-me que se tratava de uma história, um romance, exigiu atenção e resumiu a parte já lida. Um casal com filhos andava numa floresta, em noite de inverno, perseguido por lobos, cachorros selvagens. (....)

Recolhi-me preocupado: os fugitivos, os lobos e o lenhador agitaram-me o sono. Dormi com eles, acordei com eles. As horas voaram. Alheio à escola, aos brinquedos de minhas irmãs, à tagarelice dos moleques, vivi com essas criaturas de sonho, incompletas e misteriosas.(....)

Eu, pobre de mim, não desvendaria os segredos do céu. Preso à terra, sensibilizar-me-ia com histórias tristes, em que há homens perseguidos, mulheres e crianças abandonadas, escuridão e animais ferozes.

(RAMOS, 1986, p. 199-204)

Com essas palavras o menino desvenda a saúde na leitura, essas mesmas palavras levamno a interessar-se pelo mundo, atraindo-o para fora da escuridão. As junções das letras, o brilho do olhar, o resgataram das trevas.

Afastou-me da escola, atrasou-me, enquanto os filhos de Seu José Galvão se internavam em grandes volumes coloridos, a doença de olhos que me perseguiu na meninice. Torturava-me semanas e semanas, eu vivia na treva, o rosto oculto num pano escuro, tropeçando nos móveis, guiando-me às apalpadelas, ao longo das paredes.

(....)

Na escuridão percebi o valor enorme das palavras.

(RAMOS, 1986, p.138-141)

É recente a recuperação da associação entre leitura e saúde, na qual se toma o ato de ler como capaz de gerar saúde, seja pelo pragmatismo da disseminação informativa - leitura como ato pedagógico -, seja na leitura considerada como ato existencial. Ao representar a descontinuidade caótica da existência por um fluxo regular de palavras, a literatura permite a troca simbólica que sustenta o humano. Investida dessa função, oferta a leitores e ouvintes o caminho de personagens em confronto com as questões da existência. Assim, abre-se ao leitor a perspectiva de realizar as escolhas internas que vão orientar a convivência com o enigma da existência e o sentido a imprimir a ele.

\section{A LEITURA E OS BENEFÍCIOS NA SAÚDE}

A autora Eva Maria Seitz, em seu artigo, apresenta os resultados da pesquisa com o tema biblioterapia, que foi realizada com pacientes internados em clínicas médicas do Hospital 
Universitário da Universidade Federal de Santa Catarina (HU/UFSC). A hospitalização de um paciente, por qualquer que seja o motivo da patologia, é um momento gerador de conflitos. 0 desconforto pode ser de ordem física, moral, espiritual, o medo da morte gera muito sofrimento. O sentimento de solidão, de estar em lugar diferente da sua rotina pode gerar angústia, ansiedade e insegurança, que são fatores que atrapalham na recuperação do enfermo. Nesse contexto, a proposta da biblioterapia, a terapia através da leitura, teve intenção de proporcionar aos usuários do hospital momentos de alegria, descontração e lazer, manter informado dos acontecimentos externos, do mundo além das portas do hospital. A metodologia utilizada foi, em um primeiro momento, realizar um levantamento do histórico dos pacientes com a finalidade de desenvolver a forma de seleção dos mesmos para a pesquisa. No segundo momento foram organizados encontros duas vezes por semana no período da tarde, onde eram realizadas leituras. Antes da alta hospitalar foi aplicada uma entrevista, com o objetivo de avaliar a influência que a leitura teve no período de internação e o interesse pela implantação de um programa de biblioterapia. Foram selecionados 47 pacientes, sendo que dos entrevistados, 83\% aceitaram participar do programa de leitura e $17 \%$ se recusaram em participar. A grande maioria dos pacientes relata a experiência da leitura de forma positiva, indicando como seus benefícios sentimentos de paz, conforto, serenidade e bem-estar.

A pesquisa reforçou a teoria de que a leitura é uma forma de promoção da saúde mental. Através das palavras, as pessoas de modo geral, podem ter sentimentos de paz, conforto, bemestar. Esse trabalho foi realizado em um hospital, mas os benefícios da leitura podem ser sentidos em qualquer cenário, como em uma universidade, na roda de amigos, na sociedade em geral, todos podem sentir o bem-estar que a leitura proporciona.

Caldin (2005) avaliou 8 (oito) projetos de biblioterapia desenvolvidos por acadêmicos do Curso de Biblioteconomia da Universidade Federal de Santa Catarina. Embora os projetos tenham sido desenvolvidos individualmente e em ambientes diversos (colégios, brinquedoteca, instituição para tratamento de dependentes químicos e lares de idosos) os resultados obtidos em todos eles foram positivos. Nos lares de idosos, os moradores mostraram-se menos tímidos, alegres, com aumento de auto-estima e socialização. Na Instituição para tratamento de dependentes químicos, a leitura proporcionou aos internos a reflexão da superação de seus problemas. Nos colégios os alunos participaram ativamente de todas as atividades, aumentando o diálogo entre os mesmos e a expressão de opiniões pessoais.

\section{METODOLOGIA}

A investigação foi realizada através de uma abordagem qualitativa e quantitativa, tendo como instrumento um questionário objetivo (ANEXO 1), composto por 21 (vinte e uma) perguntas e dividido em dois segmentos: identificação e investigação. O segmento de identificação é composto por oito perguntas, contendo questões sobre a faixa etária, qual o curso e o semestre que o aluno frequenta, se já havia reprovado em alguma disciplina, se participa ou já participou como monitor, ou em eventos. O segundo segmento é composto por doze questões que abrangem perguntas sobre a frequência de leitura, que tipo de leitura realizam, quais os meios de leitura, se utilizam os livros impressos ou as tecnologias. Das doze perguntas de investigação as quatro últimas são de grande importância para este artigo, pois apresentam informações sobre os motivos que levam os acadêmicos a realizarem leituras, quais são os seus sentimentos, o tempo semanal que utilizam para leitura e se realizavam leitura em família.

O referido questionário foi aplicado entre os acadêmicos dos 05 (cinco) cursos de graduação oferecidos pala Universidade Federal de Pampa, campus São Gabriel: Biotecnologia, 
Ciências Biológicas bacharelado e licenciatura, Engenharia Florestal e Gestão Ambiental. Os questionários foram aplicados nas salas de aula dos acadêmicos durante o período cedido pelo professor regente, as atividades tiveram uma boa aceitação pelo corpo docente e discente da universidade.

$\mathrm{Na}$ avaliação dos resultados foi dado ênfase aos seguintes aspectos: o que os acadêmicos mais leem, como se auto avaliam enquanto leitores, que tipo de leitura utilizam e qual sua frequência.

Ao responder o questionário o acadêmico informou quais os motivos que o levam a realizar leitura, se a leitura é somente uma exigência das disciplinas, ou é uma forma de prazer, de busca pela satisfação. Foi informado também que tipo de sentimento a leitura gera nos participantes da pesquisa, tal como: alegria, desejo ou sentimentos negativos. Além disso o levantamento buscou identificar o histórico familiar, definindo qual o tempo que é utilizado para leitura individual e com a família.

\section{DESCRIÇÃO E ANÁLISE DAS RESPOSTAS AO QUESTIONÁRIO}

Responderam ao questionário os acadêmicos do curso de Biotecnologia, Engenharia Florestal, Gestão Ambiental, Ciências Biológicas Licenciatura e Bacharelado, sendo que $42 \%$ eram do sexo masculino e $58 \%$ do sexo feminino. A faixa etária apresentou-se bem variada. Embora o questionário possua vinte e uma perguntas, nesse artigo somente as quatro últimas serão utilizadas para estudo, pois as outras serão trabalhadas em outros artigos, com outros objetivos, por colegas das pós-graduação em educação. Todos os resultados obtidos nas quatro questões referidas são apresentados em forma de gráficos como segue.

Questão 2.9: Quais são seus motivos para leitura?

( ) Lazer ( ) Estudos ( ) Cultura ( ) Informação ( ) Não leio

Nessa questão, havia a alternativa de o aluno eleger mais de uma alternativa. Os resultados foram os seguintes: $45 \%$ dos acadêmicos utilizam a leitura como forma de prazer, $55 \%$ não.

(Gráfico 1.a)

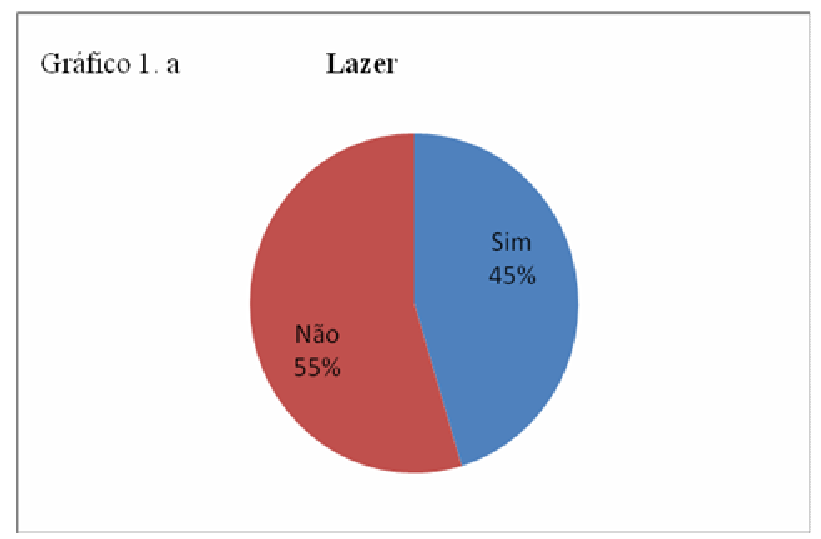

No gráfico 1.b: Percebemos que a grande maioria, $85 \%$ utilizam a leitura para estudos, $15 \%$ não. 
(Gráfico 1.b)

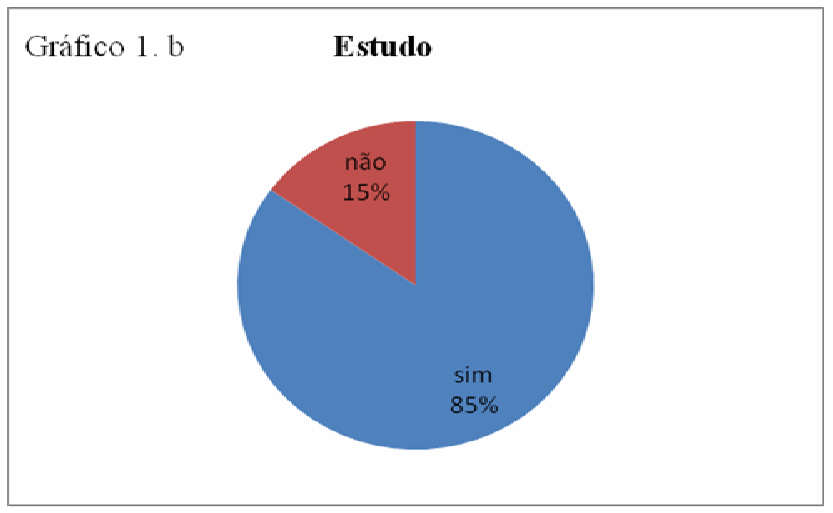

No gráfico $1 . c$ percebe-se que $45 \%$ utilizam a leitura como meio de aquisição de cultura, enquanto $55 \%$ não.

(Gráfico 1.c)

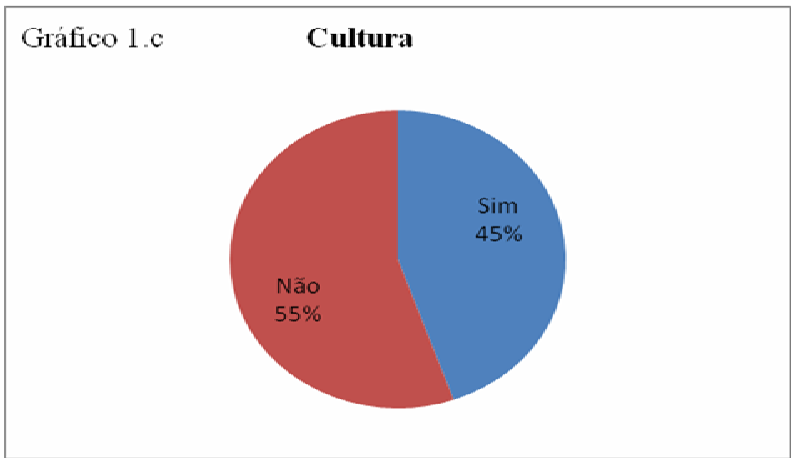

A resposta informação, $65 \%$ utilizam a leitura para obter informação, enquanto $35 \%$ não. (Gráfico 1.d)

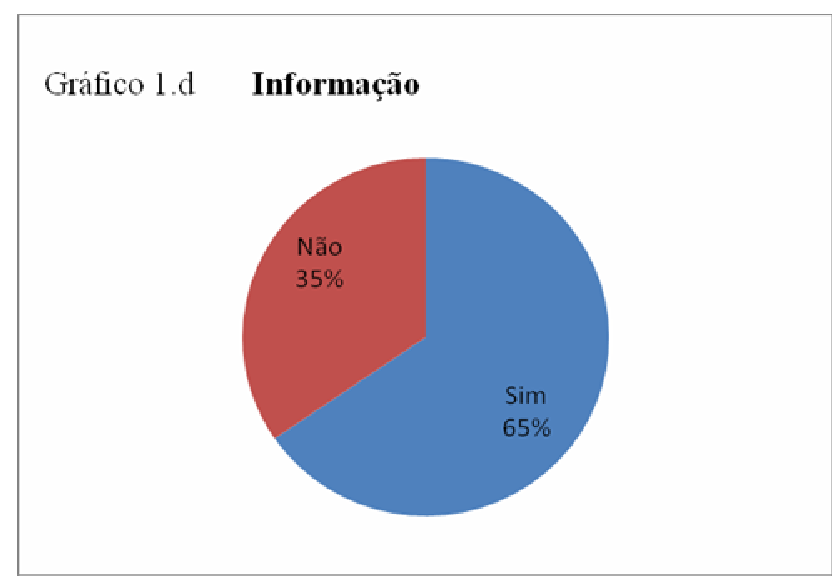

Questão 2.10: Quando você realiza as leituras quais são seus sentimentos?

( ) Feliz/Alegre ( ) Não vejo diferença de sentimentos ( ) Obrigado/Pressionado ( ) Triste/Nervoso ( ) Outros sentimentos

Quais?

Os resultados foram: $55 \%$ dos acadêmicos marcaram que se sentem felizes/alegres e $45 \%$ não marcaram. 
(Gráfico 2.a)

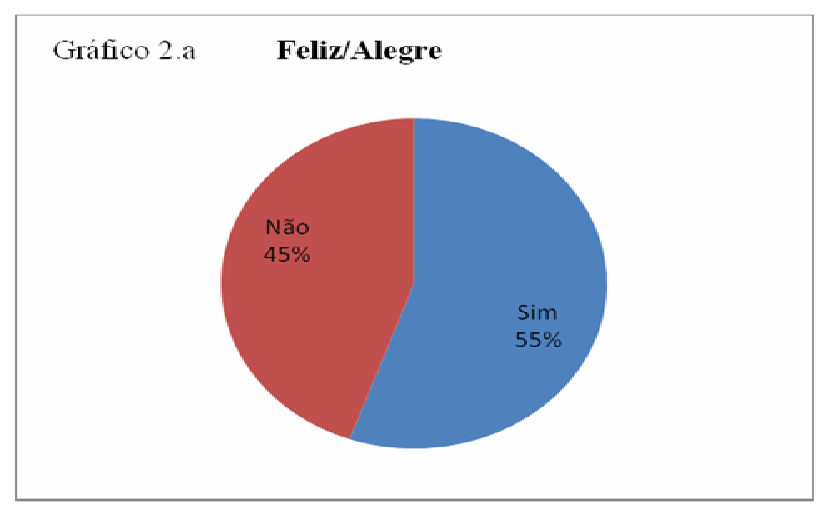

No gráfico 2.b demonstra-se que $35 \%$ dos alunos não percebem diferença de sentimentos e $63 \%$ não marcaram. Denota-se portanto, que 63\% dos entrevistados percebem algum tipo de diferença de sentimentos ao realizar a leitura.

(Gráfico 2.b)

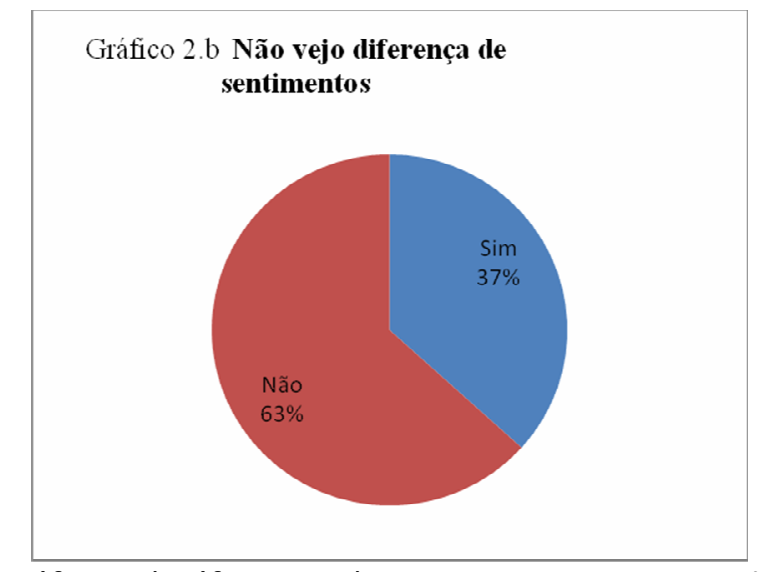

No próximo gráfico (gráfico 2.c), apenas $9 \%$ assinalaram que se sentem obrigados/pressionados ao ler, e $91 \%$ não possuem esses sentimentos.

(Gráfico 2.c)

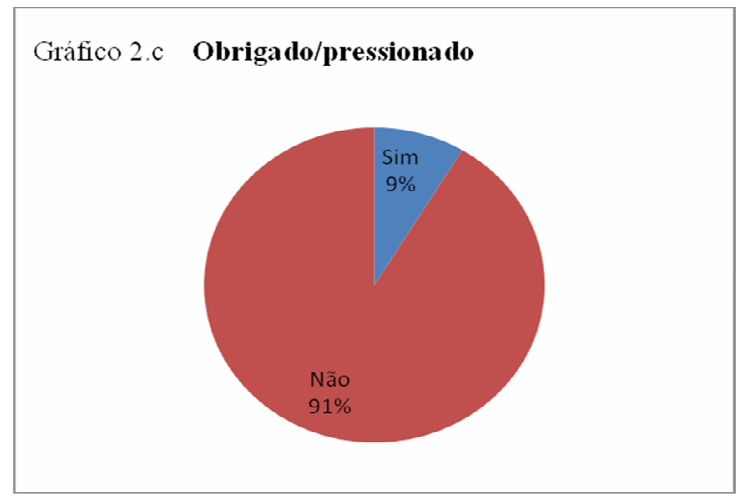

Os sentimentos de tristeza/nervosismo contemplaram a opção menos marcada pelos acadêmicos, com apenas $4 \%$ dos alunos. Os outros $96 \%$, quase a maioria, não tem esse tipo de sentimento ao realizarem uma leitura. 
(Gráfico 2.d)

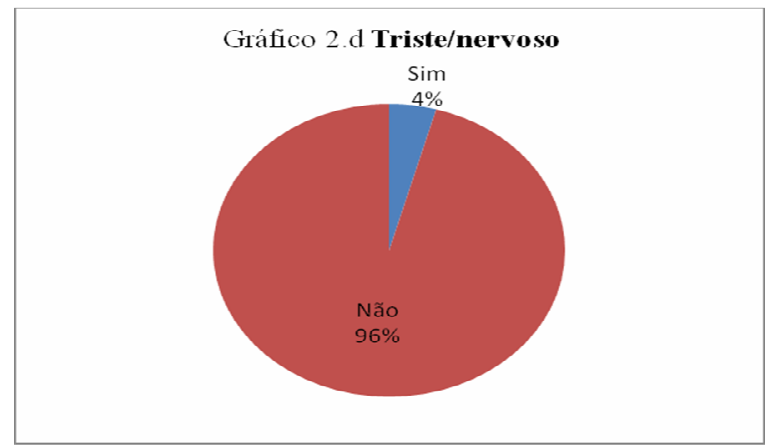

Apenas 13\% marcaram a alternativa "outros sentimentos", descrevendo em seguida que tipo de sentimento era. $87 \%$ dos entrevistados não apresentam outros sentimentos.

(Gráfico 2.e)

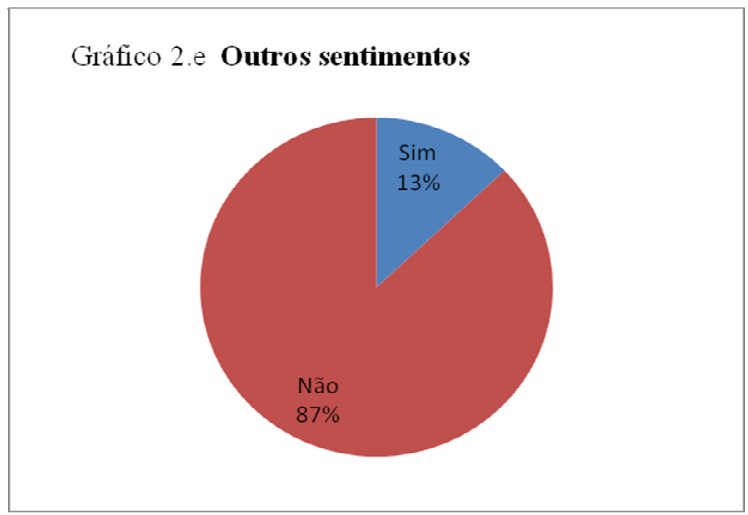

Os $13 \%$ que marcaram a questão outros sentimentos, no espaço de descrição desses sentimentos selecionaram as palavras: cansado, com sono, envolvido com a história, não sei explicar. Os resultados foram: $33 \%$ cansado, $33 \%$ com sono, $28 \%$ envolvido com a história e $6 \%$ não sei explicar.

(Gráfico 2.e.a)




Questão 2.11: Quanto tempo semanal você utiliza para leitura que lhe dá prazer?

Menos que 30min () De 30min a 1 hora () De 1 hora a 2 horas ()

2 horas a 3 horas () Mais de 3 horas()

O tempo inferior a 30 minutos teve $23 \%$ de respostas, de 30 minutos à 1 hora representou 36\% dos investigados, de 1 hora à 2 horas 19\%, de 2 horas à 3 horas 7\%, e mais de 3 horas somente $15 \%$.

(Gráfico 3)

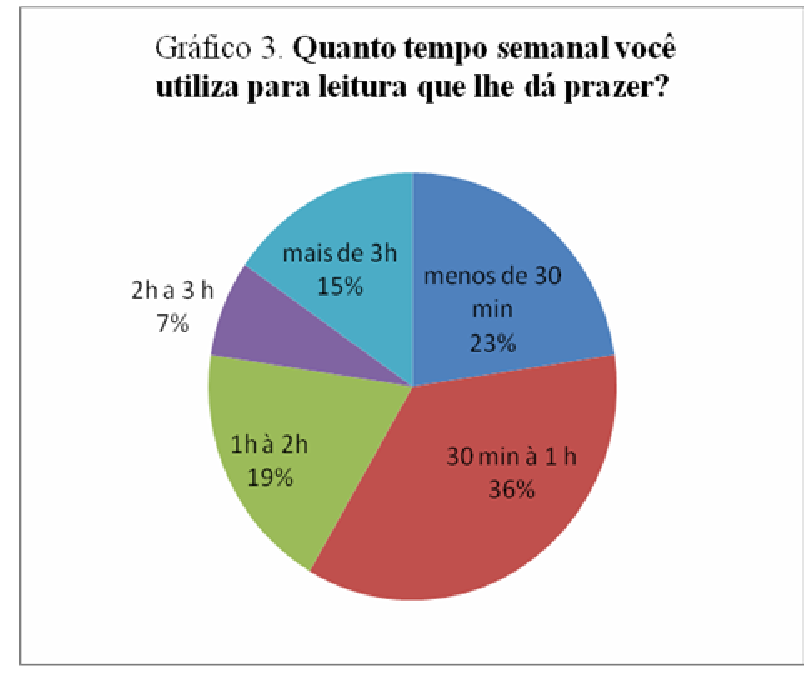

Questão 2.12: Na sua família, realizavam ou realizam leituras em grupo? (Leituras realizadas pelos adultos aos filhos, em reuniões familiares)

\section{Com frequência () Às vezes () Nunca ()}

Lembrando que hábitos que adquirimos na infância, com a família, carregamos por todas as fases da vida, os resultados foram os seguintes: apenas $10 \%$ realizaram ou realizam leitura com membros da família, $35 \%$ às vezes, e a grande maioria $55 \%$ nunca realizaram. Percebemos que infelizmente os nossos alunos não têm o hábito de ler no grupo familiar, informação essa importante, pois percebe-se que a leitura talvez não seja prioridade das famílias.

(Gráfico 4.)

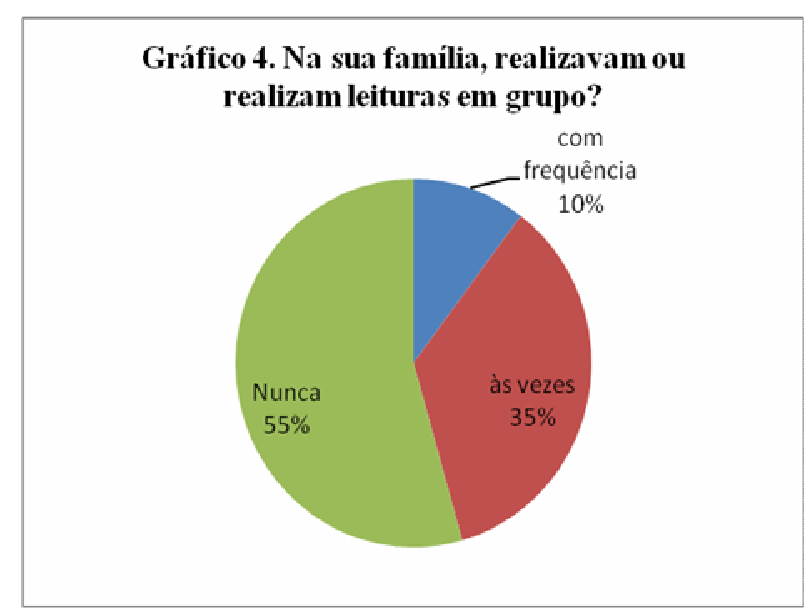




\section{CONSIDERAÇÕES FINAIS}

A leitura é uma forma obter informação, mas também serve de elo com o mundo externo. Através dos jornais, da internet, os alunos podem saber informações dos seus familiares, tendo em vista que muitos acadêmicos possuem seus entes queridos em outras cidades e estados do Brasil, trazendo assim o sentimento de estar mais próximos.

A leitura provoca bem estar para quem a utiliza, mergulhamos em um mundo diferente e totalmente novo, assim criamos um desligamento dos problemas, das angústias, das incertezas, dos medos, da solidão, proporcionando um alívio das tensões emocionais, contribuindo para o bem estar mental. Esse bem estar que a leitura proporciona, ajuda no aprendizado, gerando força para ultrapassar as barreiras, as dificuldades diárias.

A aplicação dos questionários na comunidade acadêmica dos cursos de graduação da Unipampa São Gabriel demonstrou ser útil para obtenção de dados sobre a frequência de leitura e os sentimentos produzidos por essa prática, dados importantes para traçar o perfil dos alunos da instituição. Esses resultados servirão de instrumento para professores, e para futuras ações direcionadas aos alunos.

\section{REFERÊNCIAS BIBLIOGRÁFICAS}

BOTELHO, João Bosco. História da medicina: da abstração à materialidade. Manaus: Editora Valer, 2004.

BEUTER, Magrid. Atividade lúdica : uma contribuição para a assistência de enfermagem às mulheres portadoras de câncer. 1996. Dissertação (Mestrado em Enfermagem) - Universidade Federal de Santa Catarina, Florianópolis.

CALDIN, C.F. Biblioterapia: atividades de leitura desenvolvidas por acadêmicos do curso de biblioteconomia da Universidade Federal de Santa Catarina. Revista electrónica de bibliotecnologia Archivología y Museoloría, Universidad Peruana de ciencias aplicadas 2005. FREIRE, Paulo. A importância do ato de ler em três artigos que se completam. 46. ed. São Paulo: Cortez, 2005.

BENJAMIN, Walter. Reflexões sobre a criança, o brinquedo e a educação. Trad. apres. e notas Marcus Vinicius Mazzari. São Paulo: Duas Cidades, Editora 34, 2002.

LACERDA, Nilma Gonçalves. Casa da Leitura: presença de uma ação. Filosofia e perfil da Casa da Leitura - Programa Nacional de Incentivo à Leitura / PROLER. Rio de Janeiro: Fundação Biblioteca Nacional; Casa da leitura / Proler [2002]

LACERDA, Nilma G. ; SIQUEIRA, Vera Helena F. de. ANAIS. I Seminário Nacional Saúde e Leitura Qualidade de Vida para a Criança e o Jovem - 5 a 8 de outubro de 2004. Rio de Janeiro: UFRJ, 2006.

PAIXÃO, Waleska. História da enfermagem. $5^{\text {a }}$ ed. rev. e aum. II. Newton de Figueiredo Coutinho. Rio de Janeiro: Julio C. Reis, 1979.

RAMOS, Graciliano. Infância. 23 ed. Il. Darcy Penteado; posfácio Octavio de Faria. Rio: Record, 1986. 


\section{APÊNDICE}

Figura 1 - Questionário aplicado aos alunos da Unipampa, campus São Gabriel

\section{Curso de Especialização em Educação: Interdisciplinaridade e Transversalidade Questionário de pesquisa institucional}

1. Identificação:

1.1. Qual seu sexo? Masculino () Feminino ()

1.2. Qual sua faixa etária?

16 a 18 anos () $\quad 19$ a $21 \operatorname{anos}() \quad 22$ a 25 anos

() $\quad 26$ a 30 anos () acima de $30 \operatorname{anos}()$

1.3. Qual seu curso? Biologia Bacharel ( )

Biotecnologia ( )

Biologia Licenciatura ( )

Gestão Ambiental () Engenharia Florestal ( )

1.4. Qual seu semestre?

$2^{\circ}() \quad 4^{\circ}() \quad 6^{\circ}() \quad 8^{\circ}() \quad 10^{\circ}()$

1.5. Já reprovou em alguma disciplina no ensino superior? Sim () Não () Quantas?

1.6. Participa de algum projeto de pesquisa ou extensão? Sim ( ) Não ( )

1.7. Já foi monitor? Sim ( ) Não ()

1.8. Já participou de evento acadêmico com apresentação de trabalho? Sim () Não ()

Qual evento?

Quando (ano)?

Qual modalidade (comunicação oral, pôster)?

1.9. Já publicou algum artigo acadêmico?

Sim () Não ( )

2. Investigação:

2.1. Com que frequência você lê?

Não leio () Pelo menos um dia por semana ()

Todos os dias () Não sei ou não quero opinar ( )

2.2. Você lê Jornais? Sim ( ) Não ( ) Em caso afirmativo, quais?

2.3. Você lê Revistas? Sim ( ) Não ( ) Em caso afirmativo, quais?
2.4. Você lê Livros? Sim ( ) Não ( ) Que tipo? Livros Didáticos () Livros de ficção ou poesia () Livros Técnicos () Outros () Quais:

2.5. Quais outras formas você utiliza para aquisição de conhecimento? Filmes ( ) Documentários ( ) Panfletos () Encartes () Fotografias () Quadros () Gravuras ( ) Esculturas ( ) Seminários ( ) Congressos () Cursos () Não Utilizo ()

2.6. Que tipo de tecnologia você utiliza para leitura de livros? Livro impresso () E-books () Áudio books ( ) Não utilizo ( )

2.7. Costuma ler as notícias em sítios (site) na internet? Diariamente ( ) Ocasionalmente ( ) Semanalmente () Nunca ()

2.8. Acompanha algum blog de notícias em sua área acadêmica? Diariamente ( ) Ocasionalmente ( ) Semanalmente () Nunca ()

2.9. Quais são seus motivos para leitura? Lazer () Estudos ( ) Cultura ( ) Informação () Não Leio ( )

2.10. Quando você realiza as leituras quais são seus sentimentos?

Feliz/Alegre () Não vejo diferença de sentimentos () Obrigado/Pressionado () Triste/Nervoso () Outros sentimentos ( )

Quais?

2.11. Quanto tempo semanal você utiliza para leitura que lhe dá prazer?

Menos que $30 \min () \quad$ De $30 \min$ a 1 hora ()

De 1 hora a 2 horas () 2 horas a 3 horas ()

Mais de 3 horas ( )

2.12. Na sua família, realizavam ou realizam leituras em grupo? (Leituras realizadas pelos adultos aos filhos, em reuniões familiares)

Com Frequência () As vezes () Nunca () 